\title{
CARACTERIZAÇÃO BIOLÓGICA DE ONZE ISOLADOS DE PVX (Potato virus $X$ ) DO BRASIL
}

\author{
Biological characterization of the PVX isolates (Potato virus $X$ ) from Brazil \\ Oneida de Almeida Silva ${ }^{1}$, Antonia dos Reis Figueira ${ }^{2}$, Alessandra de Jesus Boari ${ }^{3}$, \\ César Augusto Brasil Pereira Pinto ${ }^{4}$, Rafael Rodrigues Boni ${ }^{5}$
}

\begin{abstract}
RESUMO
Este trabalho foi realizado com onze isolados do Potato Vírus $X$ (PVX), sendo seis do Centro de Indexação de Vírus Minas Gerais (VIC, LAV, UF, NR, SJ, UDI), um de São Paulo (VEL), dois do Rio Grande do Sul (P21 e P22), um de Santa Catarina (CAN) e um do Distrito Federal (BR). Os isolados de PVX foram inoculados mecanicamente, em duas épocas diferentes (setembro de 2001 e julho de 2002), em hospedeiras diversas, para verificação da sua agressividade e sintomatologia induzida nos hospedeiros, com a finalidade de se fazer sua diferenciação. A diagnose foi feita por inspeção visual e DAS-ELISA. Foram feitas também tentativas de recuperação dos vírus em plantas com DAS-ELISA negativo, por inoculação nas plantas indicadoras Gomphrena globosa e Nicotiana tabacum 'TNN'. Os sintomas induzidos pelos isolados de PVX na maioria das plantas foram semelhantes, com exceção de Nicotiana glutinosa e Physalis floridana, que se revelaram ótimas diferenciadoras para os isolados VEL e P21, respectivamente. Provavelmente os 11 isolados de PVX, estudados neste trabalho, possuem a mesma origem que os isolados dos grupos 1 e 3.
\end{abstract}

Termos para indexação: Solanum tuberosum, fumo, estirpes.

\section{ABSTRACT}

This work was accomplished with eleven PVX isolates: six from national and imported seeds analised at the Virus Indexation Center of Minas Gerais - Brazil (VIC, LAV, UF, NR, SJ, UDI), one from São Paulo state (VEL), two from Rio Grande do Sul state (P21 and P22), one from Santa Catarina state (CAN) and one from the Federal District (BR). The PVX isolates were mechanically inoculated in several hosts plant, in two diferent seasons (September, 2001 and July, 2002), to verify the severity and host symptoms. The diagnosis was done by visual inspection and DAS-ELISA. Attempts to recover the PVX isolates from DAS-ELISA negative plants were also done by inoculation in the indicator plants Gomphrena globosa and Nicotina tabacum TNN. The symptoms shown by the majority of host plants, when inoculated with the eleven isolates, were similar, but Nicotina glutinosa and Physalis floridana showed distinct symptoms when inoculated with P21 and VEL. Probably, the eleven PVX isolates studied in this work have the same origin of the isolates from groups 1 and 3.

Index terms: Solanum tuberosum, tobacco, strain.

(Recebido para publicação em 12 de março de 2004 e aprovado em 20 de outubro de 2004)

\section{INTRODUÇÃO}

Na cultura da batata no Brasil, o Potato Virus $X$ (PVX) nunca esteve associado a grandes perdas, principalmente porque as sementes importadas ou estavam livres de PVX ou apresentavam um índice muito baixo desse vírus (DANIELS, 1995; DIAS, 1995; FIGUEIRA, 1995; HIRANO, 1995; LIMA, 1995). Entretanto, com a recente abertura do mercado brasileiro aos países integrantes do Mercosul, que permitem a comercialização de sementes com alta incidência desse vírus, o PVX passou a ser tratado como praga não-quarentenária regulamentada, podendo estar presente nas sementes básicas em índices não superiores a 2\% (MAPA, 2004).
O PVX encontra-se disseminado no mundo inteiro, e pode causar a diminuição do número e do tamanho dos tubérculos, induzindo perdas em torno de $10 \%$ na produção. Porém, se associado ao Potato Virus $Y$ (PVY), o PVX pode induzir sintomas mais severos e provocar perdas acima de $50 \%$ na produção (BEEMSTER \& BOKX, 1987; HOOKER, 1981; MIZUBUTI, 1981). Isso justifica os baixos índices de incidência de PVX previstos pela legislação, que estabelece as normas para produção e comercialização de batata-semente no Brasil, onde a ocorrência do PVY tem aumentado nos últimos anos (DIAS, 1995; FIGUEIRA \& PINTO, 1995; FIGUEIRA et al., 1996).

1. Departamento. de Agronomia - FESURV - Caixa. Postal 102 - 75901.970 - Rio Verde, GO.

2. Departamento de Fitopatologia - Universidade Federal de Lavras/UFLA - Caixa Postal 3037 - 37200-000 - Lavras, MG.

3. Bolsista: FAPEMIG e CBP \& D/Café - EMBRAPA

4. Departamento de Biologia - Universidade Federal Lavras/UFLA - Caixa Postal 3037 - 37200-000 - Lavras, MG.

5. Estudante de graduação - Agronomia/UFLA. 
O PVX tem uma gama de hospedeiras restrita dentro da família Solanaceae e algumas espécies de Amaranthaceae e Chenopodiaceae. O vírus não é transmitido por vetor, porém é facilmente transmitido por meios mecânicos e por enxertia, podendo ser rapidamente disseminado numa cultura, após a sua introdução através das sementes. Muitas estirpes de PVX são conhecidas e apresentam grande variabilidade patogênica. A classificação das estirpes se dá por meio de testes biológicos, sorológicos e/ou moleculares e podem ser classificadas, segundo Cockerham (1970), em quatro grupos, de acordo com a sua virulência aos genes de hipersensibilidade $\mathrm{Nx}$ e $\mathrm{Nb}$. $\mathrm{O}$ gene $\mathrm{Nb}$ confere resistência contra as estirpes dos grupos 1 e 2, ao passo que o gene $\mathrm{Nx}$ confere resistência contra as estirpes dos grupos 1 e 3. Ambos os genes, $\mathrm{Nx}$ e $\mathrm{Nb}$, não conferem resistência ao grupo 4 . As estirpes do grupo 1 caracterizamse por induzirem anéis verde-claros na superfície das folhas de fumo (Nicotiana tabacum), seguidos por um mosqueamento verde-escuro e verde-claro. Essas estirpes ocorrem principalmente associadas com as estirpes do grupo 3. As do grupo 2 são encontradas apenas ocasionalmente, apresentando em experimentos de enxertia pontos necróticos nas folhas de cultivares de batata portadora do gene $\mathrm{Nb}$. Esse grupo nunca foi observado na América do Norte e Continente Europeu (ROSS, 1986).

O grupo 3 compreende as estirpes que ocorrem mais freqüentemente. Elas causam mosqueamento claro nas folhas de fumo e, em genótipos de batata portadores do gene Nx, induzem lesões pretas nas folhas após a infecção das células. Finalmente, as do grupo 4 não ativam os genes $\mathrm{N}$, podendo infectar cultivares com genes $\mathrm{Nx}$ e $\mathrm{Nb}$, mas não aquelas com o alelo Rx (ROSS, 1986).

No Brasil, os programas de melhoramento genético estão se empenhando em desenvolver cultivares de batata brasileiras que apresentem melhores condições de adaptabilidade ao clima tropical e resistência a diversos vírus, incluindo o PVX (SILVA et al., 2000).

Segundo esses autores, uma das maiores dificuldades encontradas nesses programas é o completo desconhecimento das estirpes que ocorrem no Brasil. Ao avaliarem quinhentos e setenta clones de batata provenientes de oito famílias clonais obtidas por cruzamento biparentais entre materiais imunes aos vírus $\mathrm{X}$ e $\mathrm{Y}$, na condição simplex, originados no centro Internacional de la Papa (CIP), eles verificaram que cerca de $98 \%$ dos clones foram imunes ao isolado de PVX testado, e a proporção esperada era de $75 \%$ de clones imunes e $25 \%$ suscetíveis. Consideraram, portanto, que essa alta porcentagem de clones com imunidade ao PVX encontrada estava relacionada com o tipo de isolado empregado no trabalho.

Esses resultados corroboram com de Butzonitch et al. (1996), os quais estudaram o comportamento de clones de batata quando inoculados com diferentes isolados de PVX e PVY ${ }^{\mathrm{N}}$, oriundos da Argentina, e com isolados de PVX e PVY ${ }^{\circ}$ originários do Uruguai. Eles verificaram que isolados de PVX da Argentina induziram sintomas em $33 \%$ das plantas avaliadas, enquanto os isolados do Uruguai induziram sintomas em apenas 21\% dessas plantas. Os autores concluíram que os isolados da Argentina foram mais eficientes do que os isolados do Uruguai para identificar e selecionar os genótipos resistente aos vírus testados.

Desse modo, os resultados reforçam a necessidade de conhecer o tipo de isolado empregado nos programas de melhoramento de batata para selecionar genótipos resistentes para áreas específicas.

É importante considerar, entretanto, que o fato de o PVX não estar causando perdas na produção de batata no Brasil não significa que ele não seja capaz de afetar a produção, mas, sim, que normalmente se encontra em incidências bastante baixas na maioria dos campos (DANNIELS, 1995; DIAS, 1995; FIGUEIRA, 1995). Sabe-se, porém, que as cultivares normalmente plantadas no Brasil têm sido suscetíveis ao PVX. No trabalho de Câmara et al. (1986) ilustra-se bem a importância desse vírus no campo, onde esses autores observaram que tubérculos da cultivar Desireé, que apresentavam 10\% de incidência de PVX na terceira geração, terminaram com $35 \%$ de incidência na nona geração.

Objetivou-se com este trabalho coletar isolados de PVX provenientes dos principais Estados produtores de batata no Brasil (Minas Gerais, São Paulo, Santa Catarina, Rio Grande do Sul e Distrito Federal), afim de caracterizá-los por meio de estudos biológicos, utilizando hospedeiras experimentais com perspectivas de que esses isolados possam ser utilizados para testar a resistência de clones de batata (denominados OAS) no PVX em programas de melhoramento de batata no Brasil.

\section{MATERIAL E MÉTODOS}

Os experimentos foram realizados sob condições de casa-de-vegetação e no laboratório de Virologia Vegetal do Departamento de Fitopatologia da Universidade Federal de Lavras (DFP/UFLA) em duas épocas distintas de avaliações: setembro de 2001, com temperatura média mensal de $19^{0} \mathrm{C}$ e julho de 2002, com temperatura média mensal de $25^{\circ} \mathrm{C}$. 
Os isolados de PVX foram obtidos em brotos de tubérculos de batata infectados, provenientes das regiões de Nova Resende, Lavras, Santa Juliana, Uberlândia e Itapetininga, recebidos para análise no Centro de Indexação de Vírus Minas Gerais (IMA/UFLA) e outros isolados foram gentilmente cedidos por pesquisadores de Canoinhas - SC, Pelotas RS, Brasília - DF e Viçosa -MG (Tabela 1).

Todas as plantas utilizadas neste ensaio foram obtidas por meio de semeadura em bandejas de isopor, sendo transplantadas, posteriormente, ao atingir o tamanho ideal, para vasos com capacidade de $2 \mathrm{Kg}$, contendo, como substrato, terra, areia e esterco fumigados com brometo de metila, na proporção 3:1:1, em condições de casa-de-vegetação.

A manutenção e multiplicação dos isolados virais "in vivo" foi realizada por inoculação mecânica utilizando-se extratos de plantas infectadas, por meio de trituração em almofariz esterilizado, na proporção de $1: 5(\mathrm{p} / \mathrm{v})$ em tampão fosfato $0,01 \mathrm{M}, \mathrm{pH}$ 7, contendo sulfito de sódio na mesma molaridade. Esse extrato foi friccionado com algodão umedecido, nas folhas de Gomphrena globosa e Nicotiana tabacum, cultivar TNN, previamente polvilhadas com carborundum (500 a 600 mesh), com as mãos protegidas por saco plástico e posteriormente as folhas inoculadas foram lavadas e mantidas em casa-devegetação. Folhas de fumo infectadas por esses isolados foram dessecadas e estocadas a $-20^{\circ} \mathrm{C}$ e a $-80^{\circ} \mathrm{C}$.

Os experimentos constaram de 5 plantas por repetição e uma testemunha para cada isolado de
PVX estudado. Esses foram inoculados mecanicamente, como descrito acima, nas seguintes plantas silvestres e cultivadas: Alternanthera tenella, Bidens pilosa, Datura stramonium, Capsicum annuum 'Agronômico 10G', Chenopodium quinoa, Chenopodium amaranticolor, Gomphrena globosa, Helianthus annuus, Lycopersicon esculentum cv. 'Santa Clara', Physalis floridana, Nicandra physaloides, Nicotiana tabacum 'TNN', Nicotiana benthamiana, $N$. glutinosa, $N$. havana, $N$. glauca e Phaseoulus vulgaris. Após a inoculação, as plantas foram mantidas em casa-de-vegetação por aproximadamente 40 dias até a fase final de observação. As espécies que não apresentaram sintomas até 3 a 4 semanas após a inoculação foram submetidas ao teste de detecção de vírus por inoculação em G. globosa e pelo teste DAS-ELISA (double antibody sandwich - enzyme linked immunosorbent assay). Esse teste foi realizado empregando-se kits da Bioreba, seguindo o protocolo sugerido pelo fabricante. A leitura foi feita a $405 \mathrm{~nm}$, no leitor de placas da Dynatech laboratories, modelo MRX. Foram consideradas positivas as amostras cujas leituras de absorbância foram maiores ou iguais a duas vezes a média de absorbância dos controles, compreendido pelo suco da planta sadia (CLARK \& ADAMS, 1977) Esse procedimento foi adotado nas duas épocas de avaliações dos experimentos.

\section{RESULTADOS E DISCUSSÃO}

Os resultados da inoculação mecânica encontram-se discriminados nas Tabelas 2 e 3.

TABELA 1 - Nomenclatura e origem dos isolados de PVX estudados.

\begin{tabular}{cll}
\hline Vírus (Isolado) & \multicolumn{1}{c}{ Espécie hospedeira } & \multicolumn{1}{c}{ Origem } \\
\hline BR & Batata cv. Monalisa & Brasília - DFF \\
CAN & Batata cv. Achat & Canoinhas - SC \\
LAV & Batata cv. Monalisa & Lavras - MG \\
NR & Batata cv. Baraka & Nova Resende - MG \\
SJ & Batata cv. Monalisa & Santa Juliana -MG \\
P21 & Batata cv. Monalisa & Pelotas - RS \\
P22 & Batata cv. Monalisa & Pelotas - RS \\
UDI & Batata cv. Monalisa & Uberlândia - MG \\
UF & Batata cv. Monalisa & Lavras - MG \\
VEL & Batata cv. Velox & Itapetininga -SP \\
VIC & Fumo 'TNN' & Viçosa - MG \\
\hline
\end{tabular}




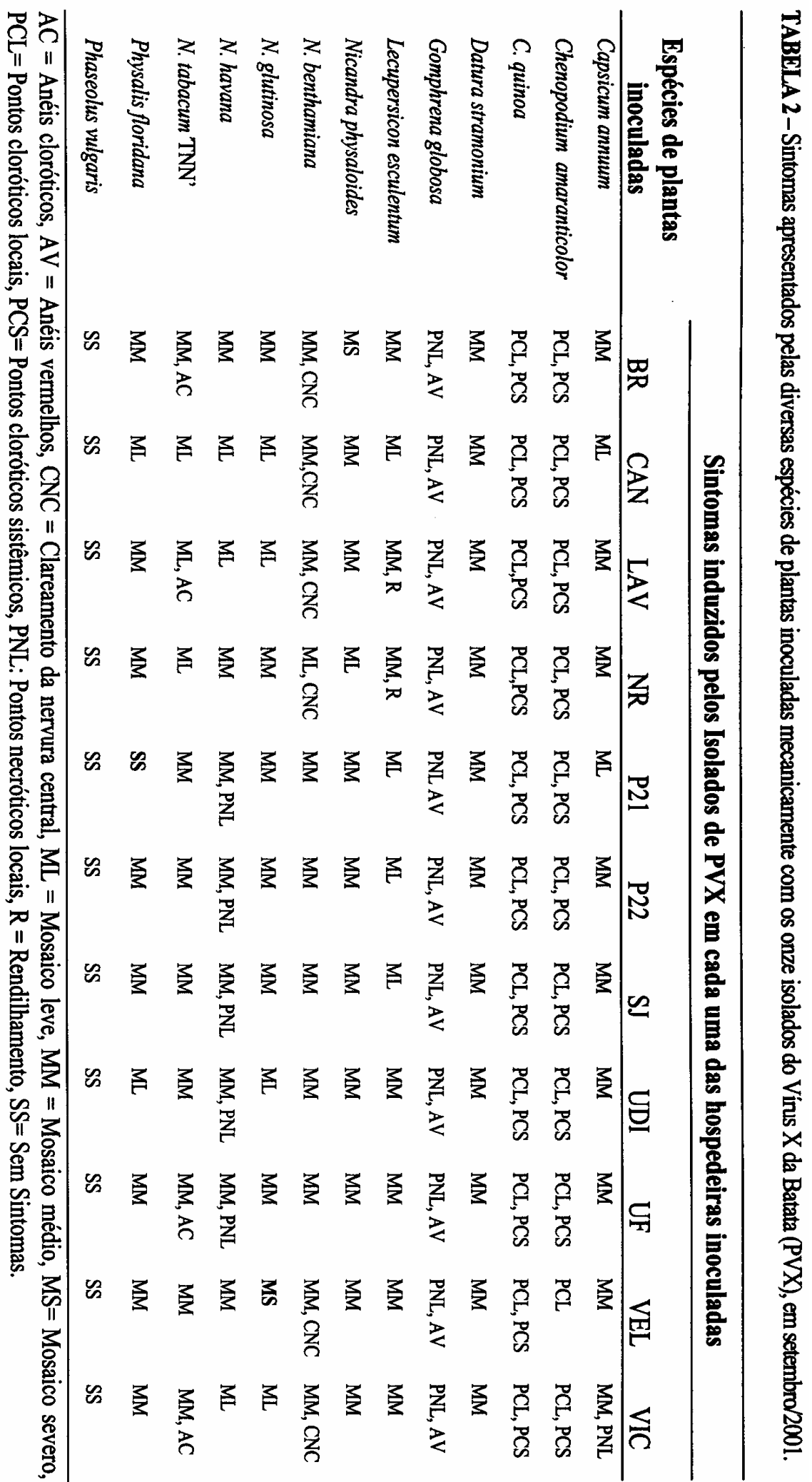

Ciênc. agrotec., Lavras, v. 29, n. 3, p. 521-527, maio/jun., 2005 


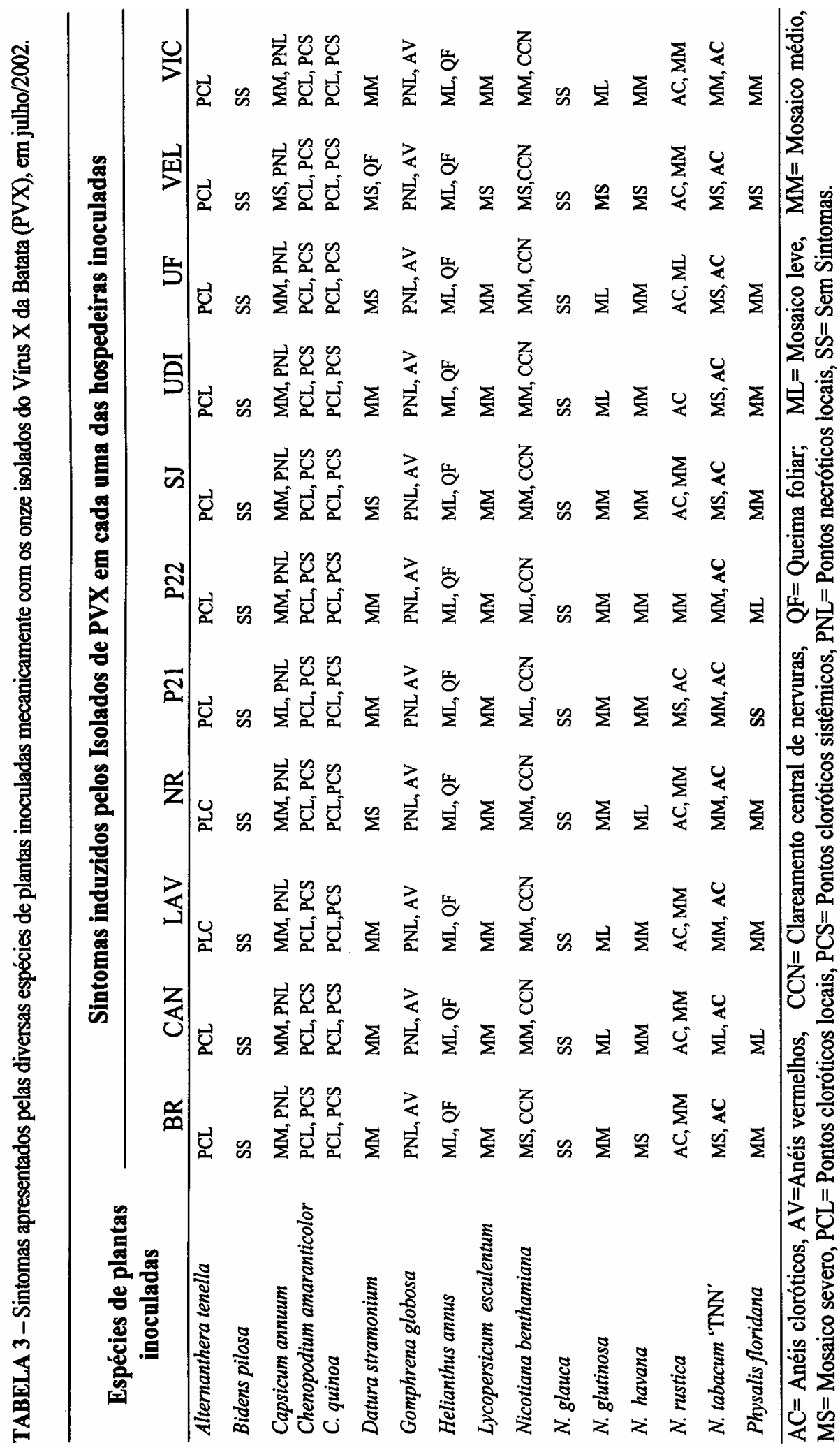

Ciênc. agrotec., Lavras, v. 29, n. 3, p. 521-527, maio/jun., 2005 
Conforme o esperado, encontraram-se diferenças entre os sintomas induzidos pelos isolados em algumas espécies hospedeiras, nas duas épocas de realização do teste, confirmando a alta influência dos fatores ambientais, tais como a temperatura, na manifestação dos sintomas induzidos pelo PVX. Segundo Mizubuti (1981) e Munro (1981), os sintomas de PVX em muitas espécies de plantas são favorecidos por temperaturas mais amenas, entre $16^{\circ} \mathrm{C}$ a $20^{\circ} \mathrm{C}$, e podem ser mascarados em temperaturas acima de $28^{\circ} \mathrm{C}$. No ensaio de setembro de 2001, a espécie de tomateiro ( $L$. esculentum cv. Santa Clara) apresentou mosaico e rendilhamento, quando inoculada com os isolados LAV e NR (Tabela 2) e mosaico médio quando essa foi inoculada com os isolados restantes. Porém, no ensaio de julho de 2002, essa hospedeira apresentou apenas sintomas de mosaico (Tabela 3). Esses resultados corroboram os de Singh (1969) que, trabalhando com a espécie Datura metel, verificou que a temperatura teve um pronunciado efeito na expressão de diferentes sintomas. As inoculações de PVX em temperatura de $13^{\circ} \mathrm{C}$ resultaram em sintomas de lesão local, ao passo que a $24{ }^{\circ} \mathrm{C}$ esses foram de mosaico sistêmico.

No girassol (Helianthus annuus), todos os isolados causaram pontos cloróticos locais, mosaico leve e queima das folhas mais velhas (Tabela 3). Os resultados obtidos neste trabalho coincidem com os de Querci et al. (1995), que observaram sintomas de pontos cloróticos locais e mosaico leve, quando inocularam girassol com as estirpes de PVX (CP4 e CP4-KR).

Nas espécies de feijoeiro (Phaseolus vulgaris) (Tabela 2), picão preto (Bidens pilosa) e Nicotiana glauca (Tabela 3), observou-se que todos os isolados testados não induziram sintomas em nenhuma das duas épocas de avaliação. Quando se tentou fazer a recuperação do vírus a partir dessas plantas por inoculação mecânica em plantas de Gomphrena globosa e de fumo (Nicotiana tabacum 'TNN'), verificou-se que o resultado foi negativo, o que também ocorreu quando as plantas foram testadas por DAS -ELISA.

Na espécie Nicotiana glutinosa, os sintomas causados pelo isolado VEL foram mais severos nas duas épocas de avaliação do experimento (Tabela 2 e 3).

A espécie Physalis floridana reagiu com sintoma de mosaico médio a todos os isolados de PVX testados (Tabelas 2 e 3), exceto com o isolado P21, proveniente do Rio Grande do Sul, o qual não induziu sintomas nas duas épocas de avaliação do experimento. Para confirmar a ausência desse isolado, procedeu-se à tentativa de recuperação a partir de $P$. floridana, por inoculação mecânica nas espécies G. globosa e fumo TNN, bem como pelo teste DAS-ELISA. Ambos os resultados foram negativos.

Devido à suscetibilidade e à diferença de reação apresentada para cada isolado, as espécies $N$. glutinosa e $P$. floridana podem ser consideradas como excelentes diferenciadoras, capazes de discriminar entre os isolados PVX VEL e P21.

Na espécie $N$. tabacum 'TNN', todos os isolados apresentaram sintomas de mosaico (leve a severo) e anéis cloróticos (Tabela 3). Esses sintomas, segundo Cockerham (1970), provavelmente classificam-se, por meio de testes biológicos, dentro dos grupos 1 e 3 das estirpes de PVX. Os isolados do grupo 2 não ocorrem na América do Norte e Europa (ROSS, 1986) e as batatas importadas pelo Brasil são provenientes de países europeus e recentemente do Canadá e Estados Unidos. Todos os onze isolados induziram sintomas de halo avermelhado, quando inoculados em G. globosa (Tabela 3), já os isolados do grupo 4 não induzem sintomas nessa espécie (BOKS \& WANT, 1987; HOOKER, 1981).

Ao fazer o seqüenciamento e, posteriormente, o alinhamento da região da capa protéica dos 11 isolados em estudo com 19 outros isolados do banco de genes, pertencentes aos grupos 1, 2, 3 e 4, Silva et al. (2003) verificaram que a maior identidade de aminoácidos (95\% a 99\%) foi com os isolados do grupo 1 e 3 .

\section{CONCLUSÕES}

a) As espécies Nicotiana glutinosa e Physalis floridana podem ser consideradas como excelentes diferenciadoras dos isolados PVX VEL e P21.

b) $\mathrm{O}$ isolado VEL foi o mais agressivo e, portanto, o mais indicado para testar a resistência de clones de batata.

c) Provavelmente os isolados de PVX, estudados neste trabalho, devem pertencer ao grupo 1 e 3.

\section{AGRADECIMENTOS}

À FAPEMIG (Fundação de Amparo à Pesquisa do Estado de Minas Gerais), pelos recursos cedidos para o desenvolvimento deste trabalho, e ao pesquisador Júlio Daniels (Pelotas - RS), que gentilmente cedeu os isolados de PVX (P21, P22 e CAN). 


\section{REFERÊNCIAS BIBLIOGRÁFICAS}

BEEMSTER, A. B. R.; BOKX. Survey of properties and symptoms. In: BOKX, J. A. de; WANT, J. P. H. van der (Eds.). Viruses of potato and seed potato production. 2. ed. Wageningen: Pudoc, 1987. p. 84-113.

BOKX, J. A. de; WANT, J. P. H. van der. Viruses of potatoes and seed-potato production. Wageningen: Pudoc, 1987. 259 p.

BUTZONITCH, I.; COLAVITA, M.; CAPEZO, S. Behavior of local isolats of PVX and PVY in the screening for resistance of potato virus $\mathrm{X}$ and $\mathrm{Y}$. Revista de la Facultad de Agronomia la Plata, Balcare, v. 101, n. 2, p. 127-132, nov. 1996.

CÂMARA, F. L. A.; CUPERTINO, F. P.; FILGUEIRA, F. A. R. Redução na produtividade de cultivares de batata causada por vírus. Horticultura Brasileira, Brasília, v. 4, n. 2, p. 8-10, nov. 1986.

CLARK, M. F.; ADAMS, A. N. Characteristics of the microplate method of Enzyme-Linked Immunosorbent assay for detection of plant viruses. Journal of General Virology, London, v. 34, n. 3, p. 475-483, Apr. 1977.

COCKERHAM, G. Genetical studies on resistance to potato viruses $X$ and $Y$. Herdedity, Edinburgh, v. 25, p. 309-348, 1970.

DANIELS, J. Viroses da batata e suas implicações na produção de batata semente no Rio Grande do Sul. Summa Phytopatologica, Piracicaba, v. 21, n. 3-4, p. 269-270, 1995.

DIAS, J. A. C. S. Viroses da batata e suas implicações na produção de batata-semente no Estado de São Paulo. Summa Phytopathologica, Piracicaba, v. 21, n. 3/4, p. 264-266, 1995.

FIGUEIRA, A. R. Viroses da batata e suas implicações na produção da batata-semente do estado de Minas Gerais: histórico do problema e soluções. Summa Phytopathologica, Piracicaba, v. 21, n. 3/4, p. 269-270, jul./dez. 1995.

FIGUEIRA, A. R.; MORAES, F. R.; PINTO, A. C. S. New PVY necrotic strain is causing great losses in Brazil. Phytopathology, Piracicaba, v. 86, n. 11, p. S85, 1996.

FIGUEIRA, A. R.; PINTO, A. C. S. Estirpe necrótica do vírus $\mathrm{Y}$ da batata em sementes importadas está causando problemas ao bataticultor mineiro.
Fitopatologia Brasileira, Brasília, v. 20, p. 299, ago. 1995. Suplemento.

HIRANO, E. Histórico e situação atual do índice de infecção de viroses nos lotes de batata semente em Santa Catarina. Summa Phytopatologica, Piracicaba, v. 21, n. 3-4, p. 271, 1995.

HOOKER, W. J. Compendium of potato diseases. Saint Paul: American Phytopathological Society, 1981. 125 p.

LIMA, M. L. R. Z. C. Viroses da batata e suas implicações na produção da batata-semente no Estado do Paraná: Histórico do problema e soluções. Summa Phytopatologica, Piracicaba, v. 21, n. 3-4, p. 272-273, 1995.

MINISTÉRIO DE AGRICULTURA, PECUÁRIA E ABASTECIMENTO. Instrução normativa. Brasilia, 2004.

MIZUBUTI, A. Principais viroses da batateira sob condições de Brasil central. Informe Agropecuário, Belo Horizonte, v. 17, n. 76, p. 4650, abr. 1981.

MUNRO, J. Potato virus X. In: HOOKER, W. J. Compendium of potato diseases. [S.l.: s.n.], 1981. p. 72-74.

QUERCI, M.; BAULCOMBE, D. C.; GOLDBACH, R. $\mathrm{W}$. Analysis of the resistance breaking determinants of potato virus X ( PVX) Straim HB on different potato genotypes expressing resistance to PVX. Molecular Plant Pathology, Binnenhaven, v. 85, n. 9, p. 10031010, 1995.

ROSS, H. Potato breeding: problems and perspectives. Berlin: Verlag Paul Parey, 1986. 132 p.

SILVA, O. A.; FIGUEIRA, A. R.; BOARI, A. J.; PINTO, C. A. B. P. Caracterização biológica e molecular de isolados do PVX (Potato Vírus $X$ ) do Brasil e triagem de clones de batata visando resistência a esse vírus. 2003. 101 p. Tese (Doutorado em Fitopatologia) Universidade Federal de Lavras, Lavras, 2003.

SILVA, O. A.; PINTO, C. A. B. P.; FIGUEIRA, A. R. Identificação de clones de batata imunes ao PVX e PVY, adaptados à região Sul de Minas Gerais. Summa Phytopathologica, Piracicaba, v. 26, n. 4, p. 297-300, 2000.

SINGH, R. Use of Datura metel L. as a local lesion host for potato virus X. American Potato Journal, Orano, v. 46, p. 355-357, 1969. 
